\title{
POR QUE ENSINO DO JEITO QUE ENSINO? Reflexões de uma Professora para Pensar a Docência em Química
}

\author{
Joyce Melo Mesquita ${ }^{1}$ \\ France Fraiha-Martins ${ }^{2}$
}

\begin{abstract}
RESUMO
Pensar em Por que ensino do jeito que ensino? possibilitou uma reflexão profunda sobre as escolhas que faço (primeira autora/narradora) como professora de Química. Nesta pesquisa narrativa autobiográfica, o objetivo é compreender se o movimento reflexivo, a partir das experiências vividas, pode se constituir em processo de autoformação e contribuir para pensar a formação e a docência em Química. A análise e a discussão dos dados estão orientadas, analiticamente, nas seguintes categorias: (i) experiências na escola - aluna e professora; ii) solidão docente - porta fechada; iii) formação continuada - porta aberta; iv) o coletivo - outros sujeitos. Tais categorias deram forma aos eixos de discussão: a) Primeiras histórias de formação e docência: da carteira escolar à porta fechada; b) Porta aberta: a contínua formação; e c) Formação e profissionalização docente: contribuições do sujeito coletivo. A análise dos dados permitiu compreender que o vivido, quando orientado por um processo reflexivo, pode contribuir para a formação docente, pois configura-se um importante mecanismo de tomada de consciência. Os resultados revelam três princípios formativos, a saber: (1) a escola é lugar de aprendizagem docente; (2) o exercício de pesquisa e reflexão é indissociável da formação e da prática docente; (3) parcerias potencializam a construção coletiva de novas práticas.
\end{abstract}

Palavras-chave: (Auto)formação; memorial de formação; aprendizagem da docência de química.

\section{WHY DO I TEACH THE WAY I DO? A TEACHER REFLECTIONS TO THINK ABOUT CHEMISTRY TEACHING}

\section{ABSTRACT}

By thinking about Why do I teach in the way I do? It has provided reflection about the choices as a Chemistry teacher (first author). On this autobiographical narrative research, the aim is to understand if the reflexive movement through the lived experience may take root in a self-education process as well as contribute to think about teachers education and Chemistry teaching. The analysis are guided, from the categories (i) school experiences - student and teacher; (ii) teaching loneliness - closed door; (iii) continuing training - opened door; (iv) the collective - other subjects. Such categories provided the following discussion: a) first teachers education stories and teaching: from the school desk to the closed door; $b$ ) opened door: the continuing teachers education; c) education and teaching professionalization: contributions to the collective subject. The analysis enabled to understand that the lived, when is guided by reflection, it may contribute to teachers education, since it is considered as an important tool of awareness. The results has shown: (1) the school is a place where it is possible to learn about teaching; (2) research and reflection are inseparable from the teachers education and teaching practices; (3) partnerships empower the collective building of new practices.

Keywords: (Self) training; training memorial; learning in the chemistry teaching.

RECEBIDO EM: 15/6/2021

ACEITO EM: 4/11/2021

\footnotetext{
1 Autora correspondente. Instituto Federal do Maranhão - IFMA - Campus Barreirinhas. MA 225, km 4. Barreirinhas/MA, Brasil. CEP 65590000. http://lattes.cnpq.br/0538038446845228. https://orcid.org/0000-0001-6399-5701. joyce.mesquita@ifma.edu.br

2 Universidade Federal do Pará (Ufpa). Belém/PA, Brasil. http://lattes.cnpq.br/4765567823575996. https://orcid.org/0000-0001-7933-6014
} 


\section{INTRODUÇÃO}

O processo de reflexão sobre a minha ação docente e as mudanças que aconteceram ao longo do meu percurso profissional não aconteceram intuitivamente; pelo contrário, eu contei com o apoio dos meus pares, muitas das constatações sobre os equívocos da minha prática foram resultados de reflexões em momentos formativos e no contato com outras pessoas, nos questionamentos, nas leituras, nas partiIhas (MEMORIAL DE FORMAÇÃO, AUTORA/NARRADORA).

O que torna desafiadora a ação de pensar sobre a docência em Química e construir conhecimento em torno dela, especificamente como o desenvolvimento profissional movimenta as escolhas docentes e vice-versa, é a percepção de que as condicionantes são muitas e que precisa ser um processo intencional com vistas à construção de conhecimento, posto que, naturalmente, a rememoração de situações cotidianas ocorre de forma despretensiosa. Como expressa a epígrafe que retrata parte de minha vida de professora, os momentos de reflexão e transformação docente são decorrentes de induções de fenômenos educativos entre a condição individual e coletiva.

Lanço mão de fragmentos de minha história para um diálogo com a coautora ${ }^{3}$ deste artigo, buscando suscitar reflexões acadêmicas. Sim, são experiências de vida e formação ${ }^{4}$ analisadas e discutidas para refletir sobre a própria vida de professora de Química, ao olhar para/de dentro da situação, construindo proposições científicas no âmbito da formação e docência em Química.

A pergunta "Por que ensino do jeito que ensino?", provocada em uma disciplina de Pós-Graduação, induziu o movimento de pensar nas escolhas que faço e porque as faço. Permitiu, ainda, perceber a construção de uma identidade profissional mediada por experiências individuais e coletivas. Pensar reflexivamente sobre as razões que me levam a ensinar, por que faço determinadas escolhas pedagógicas e como as mesmas têm orientado minha prática, deu forma ao objetivo desta pesquisa, que é compreender se o movimento reflexivo, a partir das experiências vividas, pode se constituir em processo de autoformação ao tempo de contribuir também para pensar a formação e a docência em Química.

Em termos metodológicos, assumo a pesquisa narrativa autobiográfica por entender que neste formato de pesquisa "é sempre a própria pessoa que se forma e forma-se à medida que elabora a compreensão sobre o seu percurso de vida" (NÓVOA, 2010, p. 168). Isso torna inevitável que o sujeito esteja imbricado no seu próprio processo de formação. Ainda segundo Nóvoa, esta abordagem permite ao sujeito tornar-se "ator do seu processo de formação, por meio da apropriação retrospectiva do seu percurso de vida." (p. 168).

3 Formadora de professores em Educação em Ciências que, em processos de minha formação doutoral, apresentoume dispositivos de compreensão de si para a tomada de consciência profissional pautados em Josso $(2004,2007)$, dentre eles o memorial de formação.

Mediação do conhecimento de si em sua existencialidade, que oferece à reflexão de seu autor oportunidades de tomada de consciência sobre diferentes registros de expressão e de representações de si, assim como sobre as dinâmicas que orientam sua formação (JOSSO, 2007, p. 419). 
Além disso, para Clandinin e Connelly (2011), a pesquisa narrativa constitui-se em método de investigação que possibilita a mediação entre a história individual e a história social. Histórias passíveis de serem refletidas em outros contextos (FERRAROTTI, 2010). Nesses termos, considero como os autores que processos investigativos que lidam com as experiências de vida e formação de um indivíduo atribuem valor de conhecimento à subjetividade.

Assim, ancorada em Clandinin e Connelly (2011), recorro ao meu memorial de formação como texto de campo para a obtenção dos dados da pesquisa narrativa. $O$ processo de análise pauta-se na metodologia da Análise Textual Discursiva (ATD), que considera a desmontagem dos textos de campo em busca de unidades de significado, em que, por meio do estabelecimento de relações (processo auto-organizativo), dá-se forma às categorias analíticas (MORAES; GALIAZZI, 2016).

A partir do processo de ATD emergiram quatro categorias analíticas: (i) experiências na escola - aluna e professora; ii) solidão docente - porta fechada; iii) formação continuada - porta aberta e iv) o coletivo - outros sujeitos. Tais categorias deram forma aos seguintes eixos de discussão e organização deste artigo: a) Primeiras histórias de formação e docência: da carteira escolar à porta fechada; b) Porta aberta: a contínua formação; e c) Formação e profissionalização docente: contribuições do sujeito coletivo.

\section{PRIMEIRAS HISTÓRIAS DE FORMAÇÃO E DOCÊNCIA: da Carteira Escolar à Porta Fechada}

Ao pensar retrospectivamente sobre os processos de formação docente pelos quais passei, tornou-se evidente que, ao contrário do que supunha, a formação profissional docente não inicia na Graduação, não é resultado apenas da Licenciatura e, muitas vezes, sofre mais influência de fatores anteriores e inconscientes do que de fatores intencionais promovidos pela formação universitária. A esse respeito, Josso (2010, p. 62) enfatiza que "a mudança está longe de passar unicamente pelas escolhas voluntárias e/ou lógicas". A autora ressalta que o processo de (trans)formação do sujeito professor não depende exclusivamente das escolhas (conscientes ou não) que faz, mas é afetado, também, pelas escolhas de terceiros que marcaram sua trajetória de vida e formação.

A aprendizagem da docência sofre influência das experiências do sujeito na condição de aluno e, muitas vezes, as experiências evocadas remetem à educação básica. A depender da qualidade das experiências vivenciadas na formação inicial docente, o (futuro) professor encontra soluções para a sua docência ao recorrer à memória de quando era estudante da educação básica. Em geral, isso ocorre quando o processo de formação inicial deixa lacunas ao dissociar a teoria da prática, ignorando o contexto da escola e provocando danos significativos à profissionalização docente, por compreender que as exigências únicas para ser um bom professor de Química incluem o domínio do conteúdo químico e uma boa base pedagógica que facilite a "transmissão" do conteúdo (SCHNETZLER, 2002).

Nesses casos, o professor inexperiente recorre às memórias que possui da escola e da prática dos professores que teve, buscando resgatar algo que lhe dê suporte, que Ihe ampare no início da carreira docente, esperando que, a partir de um processo de 
imitação, seja possível construir uma identidade própria (MALDANER, 2013). O grande risco neste processo inicial de docência reside no fato de que, geralmente, este profissional se encontra sozinho para realizar as reelaborações e ressignificações necessárias à sua prática docente.

Inspirada, portanto, por essas questões e em busca de respostas à pergunta orientadora desta pesquisa, passei a ir e vir em minhas memórias na intenção de ultrapassar algumas compreensões sobre formação e docência e de fazer emergir as experiências formativas pelas quais passei. Antes de ser uma professora de Química, fui aluna. As memórias de aluna no contexto da escola estão presentes e influenciam minhas compreensões sobre ensino e aprendizagem, mas não determinam minhas práticas docentes.

Considero que o movimento de pensar sobre essas práticas é que pode mover-me para frente, adiante. Esse movimento, porém, precisa ser orientado por uma intencionalidade que conduz à reflexão sobre minhas experiências e sobre a tomada de consciência em termos teóricos e práticos, aspirando melhoria da docência. Foi assim que rememorei as aulas de Ana, quando fui sua aluna na escola.

Durante muitos momentos, escutei Ana falar sobre desigualdades, escola pública (mesmo o nosso ambiente sendo uma escola particular, com muitos recursos e estrutura adequada), estratificação social, pobreza, minorias, distribuição de renda... Ela tinha uma forte preocupação com a nossa formação crítica, e isso se manifestava nas escolhas dela para os temas de redação, para debates e organização dos textos que líamos. Foi Ana que me falou pela primeira vez o que significava ser "cidadã", ter pensamento crítico e ético. Naquele momento eu vivenciava, mesmo na condição de aluna, que a docência tem uma relevância intrinsecamente social e política. Hoje, sendo professora de Química, não consigo pensar na educação de forma dissociada dos problemas sociais, compreendo a escola como uma extensão da sociedade e os problemas que assolam esta última não isentam a primeira (MEMORIAL DE FORMAÇÃO, AUTORA/NARRADORA).

O movimento de pensar retrospectivamente nas escolhas que faço ao ensinar Química remeteu-me à Ana, à sua prática como professora de Português e Redação na escola, preocupada com a formação crítica dos seus alunos. O resgate das minhas experiências com a professora Ana, isto é, de trazer à tona o passado para interpretá-lo com o olhar do presente, me fez compreender que existe muito das minhas experiências como aluna presente na minha prática docente.

A experiência de ser aluna de Ana me marcou e isso contribuiu para o meu desenvolvimento profissional e para a compreensão de um ensino mais comprometido com a justiça social. Assumo, portanto, que não sou uma professora neutra e preciso desempenhar um papel consciente no ensino que me proponho a praticar, pensando sempre nas implicações sociais e políticas da minha ação docente (ZEICHNER; DINIZ-PEREIRA, 2005).

O sentimento de compromisso social e a consciência ética em minha profissão foram, de algum modo, constituídos também pelas interações com a professora Ana, no contexto social da sua sala de aula, sendo amadurecidos ao longo da minha profissiona-

Os nomes extraídos do memorial de formação e apresentados ao longo do texto são fictícios. 
lização. Considero, entretanto, que não é possível esperar que apareçam "Anas" na vida de pessoas que futuramente se tornarão professores. É necessário prever na formação docente ações que propiciem sentimentos e tomada de consciência no âmbito da ética e da justiça social em prol da profissionalização docente.

Nessa perspectiva, Contreras (2002, p. 79) destaca que:

Somente nos contextos sociais, públicos, a obrigação ética pode alcançar sua dimensão adequada. Isso se refere, em primeiro lugar, ao contexto profissional, no qual as associações de professores, seja em seus próprios centros ou em outros âmbitos de agrupamento ou organização, desenvolvem sua profissionalidade na medida em que compartilham problemas, discutem princípios, contrastam alternativas e soluções, analisam os fatores que condicionam seu trabalho, organizam sua ação etc.

A tomada de consciência da influência da Ana em minha constituição docente foi produzida por meio da reflexão intencional sobre minhas experiências de vida e formação, o que indica o desenvolvimento de um processo (auto)formativo. Inspirada em Josso (2010) e Clandinin e Connelly (2011), considero que as produções de narrativas sobre as experiências vividas são processos educativos, pois, quem conta, revive a sua história e a ressignifica, saindo do passado para o presente e projetando o futuro, e, quem a ouve ou lê, revive a sua própria história, atribuindo-lhe novos sentidos e significados.

Dando continuidade ao movimento reflexivo que me foi provocado para pensar sobre o ensino de Química que pratico, rememoro o meu primeiro dia de aula na escola na condição de professora. Ao lembrar-me desse passado tomo consciência das sensações e sentimentos que me acometeram no início da carreira docente, conforme expresso:

Eu consigo lembrar com muita clareza do meu primeiro dia na turma após uma rápida apresentação, interrompida várias vezes com o pedido de silêncio. A coordenadora se despediu de mim e "fechou a porta". A sensação da porta fechada me alimentava na certeza de que seríamos somente nós, eu e cerca de trinta e cinco alunos (MEMORIAL DE FORMAÇÃO, AUTORA/NARRADORA).

Uma porta fechada configura-se uma boa metáfora ao processo de iniciação de um professor no ambiente da escola, e poucas iniciativas se direcionam a auxiliar o professor quando este começa sua jornada na docência. Isto demonstra que ainda predomina a compreensão de que a formação inicial de um professor é suficiente para subsidiar sua ação docente e, desse modo, a Licenciatura daria cabo das necessidades formativas. Contrário a este pensamento, Zeichner (1993) defende que a aprendizagem da docência é um processo que não se encerra na formação inicial; ao contrário, o que a academia pode proporcionar ao aluno-mestre, na melhor das hipóteses, é prepará-lo para começar a ensinar.

O "começar a ensinar" não é um momento fácil para um professor iniciante. Precisei organizar todo o conjunto de conhecimento teórico e, até mesmo, os poucos conhecimentos práticos que desenvolvi nas disciplinas específicas de aprendizagem da docência (práticas de ensino e estágios supervisionados) para mobilizá-los em minhas aulas. De forma distinta ao que vivenciei na Licenciatura, quando a teoria e a prática 
estão dissociadas e compõem grupos separados de disciplinas, a realidade da sala de aula exigia uma maior integração de conhecimento e eu não dispunha de tempo ou da possibilidade de questionar a um professor supervisor. Eu era a professora; cabia a mim orientar as discussões e mediar os conflitos que iniciaram tão logo a coordenadora pedagógica fechou a porta.

Usei o tom mais grave que pude naquele momento e pedi que fizessem silêncio. Eles me olharam com certa descrença na possibilidade de eu ficar; cochichavam, sorriam, estavam quase certos de que eu não retornaria no dia seguinte e alguma coisa dentro de mim pedia isso (MEMORIAL DE FORMAÇÃO, AUTORA/NARRADORA).

Nenhuma disciplina da Licenciatura seria capaz de ensinar com fidedignidade sobre o turbilhão de emoções que ocorre no ambiente de um primeiro dia de aula de um professor iniciante; mesmo nos momentos em que o licenciando recorre à escola para observação ou até na regência de sala de aula. Surge o nervosismo; os alunos que parecem sentirem de longe os nossos temores; percebe-se a comum indiferença dos outros setores da escola, até mesmo dos colegas de profissão mais experientes que, muitas vezes, me orientaram a mudar de carreira.

Nada parece cooperar com o professor inexperiente; "a confrontação inicial com a complexidade da situação profissional, o tactear constante, a preocupação consigo próprio [...] a distância entre os ideais e as realidades quotidianas da sala de aula" (HUBERMAN, 2000, p. 39). Tudo isso torna-se mais agravante quando a escola onde trabaIhamos tem problemas sociais sérios (indisciplina, pobreza, abandono familiar e pedagógico, violência, drogas, etc.), como foi o caso da minha primeira experiência.

Era inevitável sentir-me isolada e não demorei a perceber que as expectativas que recaíam sobre mim esperavam que eu resolvesse as necessidades e urgências da minha sala de aula sozinha. Freedman, Jackson e Boles (1983) revelam, na obra de Zeichner (1993, p. 58), que

Uma das consequências deste isolamento individual dos professores e da falta de atenção ao contexto social do ensino no desenvolvimento profissional do professor é o facto dos professores verem os seus problemas como sendo só deles, não relacionados com os dos outros professores ou com a estrutura das escolas e dos sistemas educativos.

Ao refletir sobre meus sentimentos naquele primeiro momento com a turma, reconheço nesses autores que eu considerava, sim, que os problemas ali eram somente meus. Fui, ao longo do tempo, mediando conflitos, ressignificando os conhecimentos científicos aprendidos na universidade para torná-los adequados à educação básica, desenvolvendo diferentes estratégias de ensino, reorientando práticas que não funcionaram, e percebi que este movimento foi fomentando a construção de conhecimentos da prática.

O resgate dessa experiência inicial fez-se tomar consciência, pautada em Imbernón (2006), de que eu vivi nesse momento profissional, logo após a graduação, o chamado período de iniciação à docência, no qual a prática educacional foi me conduzindo à consolidação de determinado conhecimento profissional, envolvendo esquemas, pautas e rotinas da profissão. Imbernón (2006) considera que esse conhecimento está 
estreitamente ligado à ação, constituindo-se em "conhecimento pedagógico especializado" que se refere a um conhecimento prático que integra os conhecimentos das disciplinas aos procedimentos adotados pelo professor para reagir às situações complexas e dinâmicas na sala de aula, emitindo "juízos profissionais situacionais" a partir do conhecimento experimental na prática. Ribeiro, Bejarano e Souza $(2007$, p. 13) corroboram esse entendimento ao afirmarem que

Os acontecimentos no dia-a-dia de uma sala de aula levam o professor a utilizar os conhecimentos que dispõe e muito de sua intuição, sendo capaz de resolver problemas de várias ordens. Assim, ele aprende com as experiências, bem e mal sucedidas, e constrói conhecimentos referenciais que o ajudarão a avaliar os futuros acontecimentos e situações (grifo nosso).

Tanto Imbernón (2006) quanto Ribeiro, Bejarano e Souza (2007) ajudaram-me a compreender que em meu processo inicial de docência fui desenvolvendo conhecimentos de ordem prática, construídos no cotidiano da sala de aula. Embora, contudo, compreendesse o valor daquele conhecimento para o meu trabalho docente, naquele tempo eu ainda não conseguia enxergar conexões teóricas, pois em nada se assemelhavam ao que estudei e aprendi na formação universitária.

Ao buscar refletir sobre os modos formativos pelos quais eu transitei na Graduação, percebi que vivenciei o modelo da Racionalidade Técnica, com o foco nos conhecimentos da ciência básica e suas técnicas, pois fui submetida ao ensino dos conteúdos específicos da Química sobreposto às discussões de problemas que ocorrem na atuação cotidiana do professor de Química. Isso justifica porque eu, naquele momento, não conseguia fazer conexões teóricas ao que estava praticando em aula: a teoria da docência me foi ensinada destituída da prática de ensino de Química.

Daí a sensação que tinha do conhecimento, que fui construindo a partir do desenvolvimento da minha prática docente, ser a-teórico, pois em minha formação inicial não houve espaço para que o conhecimento prático do professor se constituísse como científico. Outra questão importante diz respeito à ausência de validação desse conhecimento prático, porque os critérios utilizados para tal validação são os mesmos para o conhecimento específico, de ordem científica ou técnica. Ainda existem formadores de professores atuando em cursos de Licenciatura que não reconhecem a pesquisa dos professores no cotidiano escolar como uma produção do conhecimento (ZEICHNER; DINIZ-PEREIRA, 2005).

Diante do modelo de formação de professores de Química do qual participei, pautado em proposições QUE não valorizam a produção do conhecimento no cotidiano escolar, como poderia eu, no início de carreira docente, pensar diferente? Ou considerar que eu seria capaz de produzir conhecimento científico por meio das minhas próprias práticas?

Na linha da discussão em ser científica ou não a produção de conhecimento sobre a própria prática do professor, Zeichner (1998) defende não ser coerente fazer uso dos mesmos recursos adotados nas pesquisas acadêmicas para julgar o mérito das pesquisas de professores. Para o autor, as investigações realizadas por docentes devem ser avaliadas quanto à clareza na apresentação das ideias, ao critério de subjetividade e de validade dialógica. 
Minha primeira experiência na docência foi um processo intenso e desafiador, posto que provocou em mim o entendimento de que era necessário desenvolver outros conhecimentos para organizar e sistematizar meu cotidiano docente. Não sabia ao certo como fazer, mas com o passar do tempo fui compreendendo a necessidade de mobilizar diferentes conhecimentos teóricos e práticos no espaço da escola, mas eu continuava sozinha e a porta permanecia fechada.

Assim, as necessidades formativas que identifiquei na minha primeira experiência na docência e na formação inicial me fizeram perceber que eu precisava me envolver mais com o exercício da pesquisa em busca do conhecimento teórico-prático. Nesse início de minha carreira docente encontrei no Pibid ${ }^{6}$ uma oportunidade de ir, continuadamente, por meio de processos de investigação sobre a minha prática (MACENO; GUIMARÃES, 2014), superando minhas dificuldades na docência, uma vez que me mantive participante desse programa desde a Graduação.

\section{PORTA ABERTA: A Contínua Formação}

[...] eu parei para pensar sobre o que acontece quando desligamos o aparelho de datashow e nos despedimos daqueles sujeitos. Será que continuam pensando sobre o que fora discutido na oficina? Será que vai existir alguma mudança nas suas práticas? Será que eles retornam para outros momentos como esse? A verdade é que quando os professores saem dos momentos formativos, como a própria oficina - por melhor que tenha sido o momento - ao retornarem à escola a realidade vivenciada é a mesma (MEMORIAL DE FORMAÇÃO, AUTORA/NARRADORA).

O excerto extraído do memorial que constitui esta epígrafe revela um primeiro momento de reflexão sobre a importância da formação continuada para professores de Ciências/Química. A minha primeira experiência no Pibid surgiu ainda como aluna da Licenciatura e permitiu o contato com outros professores da educação básica, licenciandos e professores universitários, para discutir o ensino de Química e, consequentemente, a formação de professores para este ensino. O Pibid esteve presente em um longo percurso do meu processo de formação inicial e continuada. Participei do Programa na condição de bolsista-licencianda, mais tarde como supervisora-professora da educação básica e, posteriormente, como pesquisadora-voluntária, uma vez que continuei engajada ao Pibid para o desenvolvimento da pesquisa-ação que resultou em minha dissertação de Mestrado.

Grande parte das atividades do Pibid que envolvia a pesquisa e a formação dos professores de Química ocorria em forma de oficinas programadas, as quais eram planejadas em subprojetos do Pibid, que se configuravam no âmbito da formação inicial e continuada de professores de Química. A esse respeito, narro duas situações distintas de oficinas que desenvolvemos em que a participação dos professores e as discussões ocorreram de maneiras distintas, propiciando compreensão diferenciada no que diz respeito à participação dos professores e às reflexões sobre a formação docente.

O Programa Institucional de Bolsas de Iniciação à Docência iniciou um subprojeto na Licenciatura em Química da Universidade Estadual Vale do Acaraú - UVA - a partir do ano de 2010 e integrou professores em serviço com licenciandos e professores universitários em iniciativas de formação. 
A primeira oficina promovida pelo subprojeto de Química do Pibid foi realizada com professores de uma mesma escola que foram convocados pela gestão para participar da atividade com a alegação de que a quinta-feira seria o dia destinado ao estudo ${ }^{7}$ da área de Ciências da Natureza. O dia configurava-se muito mais um momento para atender à burocracia da profissão docente do que efetivamente momento de estudo e formação da área. A obrigatoriedade de participar da oficina não tornou o ambiente da escola receptivo; os professores demonstravam insatisfação com a nossa ${ }^{8}$ presença e tal insatisfação se tornava mais evidente a cada momento sugerido durante o desenvolvimento da atividade.

Destaco, do meu memorial, que "senti certa preocupação, pois sabia que a programação da oficina contava com um possível diálogo posterior à palestra e atividades planejadas para gerar um ambiente dialogado e colaborativo" (MEMORIAL DE FORMAÇÃO, AUTORA/NARRADORA). Não havia nenhum interesse dos participantes da oficina em colaborar com as discussões e, muitos deles, pareciam discordar dos assuntos abordados. Hoje, ao refletir sobre esse momento de pesquisa e formação ocorrido por meio da oficina, compreendo que não houve respeito com o professor-participante na condição de sujeito em formação.

Para Schnetzler (2002, p. 15), "muitas vezes, o professor não se sente compromissado com a pesquisa acadêmica, pois nela tem sido desconsiderado como sujeito produtor de saberes". Considero que o primeiro erro que cometemos nesta experiência foi não perguntar a eles, atores principais daquela escola, quais as necessidades reais para sua escola, para os problemas que enfrentavam, para atender aos seus anseios profissionais.

Não demorou muito e os próprios professores participantes apontaram as fragilidades da oficina. Destaco aqui a fala de um dos professores com mais de dez anos de docência, que aproveitou o momento de "discussão em grupo" para mencionar, com ironia e desdém: "a carga horária que possuía, os problemas de indisciplina da escola, quanto ganhava e todas as questões que o faziam acreditar que o momento da oficina era mais uma perda de tempo!" (MEMORIAL DE FORMAÇÃO, AUTORA/NARRADORA).

A fala do professor, extraída de meu memorial, atingiu-nos fortemente e provocou, em um primeiro momento, a sensação de revolta, indignação. Reviver este momento me fez perceber que, à época, me senti ressentida; "só pensava na nossa dedicação para o momento e a verdade é que os resultados da oficina foram bem distantes das expectativas que tínhamos" (MEMORIAL DE FORMAÇÃO, AUTORA/NARRADORA). Lendo e refletindo sobre essa experiência, porém, compreendo que a amargura das palavras do professor revelou o cansaço de alguém que estava sendo mais uma vez desconsiderado. No momento da oficina, quando discutíamos os desafios do ensino de Ciências na educação básica, ninguém possuía mais propriedade para discorrer sobre o assunto dentro daquele contexto do que aqueles profissionais. Aponto, ainda em meu memorial, que

Cada área possuía um dia na semana onde os professores não são lotados em disciplinas para poderem realizar planejamento das aulas, preenchimento dos diários e reuniões de alinhamento.

8 As ações desenvolvidas pelo Programa eram construídas e executadas na parceria entre o coordenador do subprojeto (professor formador) e os licenciandos bolsistas do Programa. 
[...] a ideia era melhorar o ensino de ciências e, ingenuamente, acreditávamos saber como. O problema é que não conhecíamos a escola, seus desafios, a gestão, os alunos, a comunidade e fomos arrogantes a ponto de propormos alternativas para seus problemas; dizer que tipo de mudanças deveria acontecer na escola que conhecemos poucos meses antes da oficina e o tempo que passamos nela, não ultrapassava quatro horas semanais, que se dividiam em aplicação de questionários e observação do cotidiano escolar (MEMORIAL DE FORMAÇÃO, AUTORA/ NARRADORA).

Assim como em nossa proposta, muitas das iniciativas de formação continuada permanecem subtraindo do professor o direito de definir objetivos, refletir na/sobre/ para a própria prática, investigar desafios, propor caminhos de superação e assumir, de forma autônoma e consciente, o compromisso com sua própria formação.

A respeito da oficina, lembro-me que, após essa experiência formativa, o grupo vinculado ao subprojeto de Química do Pibid reuniu-se para discutir os resultados, ler os materiais produzidos, refletir sobre o momento e as necessárias reelaborações que deveríamos fazer para que os aspectos negativos dessa proposta não se repetissem. Uma ruptura inicial efetiva que assumimos foi o abandono dos slides utilizados na primeira oficina, todos construídos com afirmações, tópicos, definições e citações. Queríamos a participação do professor, mas não havia espaço para esta participação. Os slides que produzimos já apresentavam respostas e estavam tão cheios da presunção de ensinar algo aos professores que não consideravam a possibilidade de que pudéssemos aprender com a experiência deles.

A elaboração de nova proposta de formação que desenhamos para as oficinas subsequentes foi desenvolvida a partir de encontros para discussão dos resultados da primeira oficina. Ler, refletir e analisar o material produzido pelos professores e os registros realizados na ocasião da oficina permitiram uma imersão sobre nossas próprias crenças e concepções acerca da formação do professor e seu papel no processo de ensino e aprendizagem.

O resgate das memórias que tenho desses encontros revelou um desafio ao trabaIho do grupo: havia um abismo significativo entre a formação que idealizávamos e aquela que se efetivava a partir das propostas formativas que desenhamos, e este abismo só poderia ser superado com a participação efetiva dos professores no desenvolvimento das oficinas.

Rememorar tais experiências possibilita-me compreender que não havíamos superado nossas próprias limitações de formação, arraigadas no positivismo, que supõe o formador como detentor do conhecimento. Ao contrário, em um movimento processual de vir a ser, é fundamental que em propostas de formação continuada o professor-participante ultrapasse o modelo de transmissão em busca de significar suas práticas educativas com vistas à construção do conhecimento, devendo as ações do formador pôr em evidência tais práticas para estudo e retroalimentação da docência (CARVALHO; GIL-PÉREZ, 2006; FRAIHA-MARTINS, 2014).

Ainda colocando em destaque minha narrativa de formação, expresso que, embora nosso grupo do Pibid objetivasse romper com a concepção do professor reprodutor de conhecimento, buscando torná-lo autônomo e sujeito da própria aprendizagem, aca- 
bamos por desenvolver práticas na primeira oficina que cercearam o direito do professor de selecionar seus próprios objetivos e de investigar os desafios postos à sua prática. Assim relato no memorial:

[...] estavam agendadas outras oficinas e a primeira experiência nos evidenciou que deveríamos tentar outro caminho de aproximação com os professores das escolas. A questão principal era definir e pensar em ações que pudessem, de fato, possibilitar a discussão que pretendíamos (MEMORIAL DE FORMAÇÃO, AUTORA/ NARRADORA).

Desse modo, era fundamental alterar o planejamento das atividades de formação do Programa, mesmo conscientes, à época, de que estaríamos arriscando ao considerar a incerteza das falas dos professores no processo de construção da proposta formativa ali em questão, conforme destaco:

decidimos construir slides com questionamentos. Assumimos um risco e aquela experiência foi marcante e decisiva para o entendimento de que qualquer ação que objetive formar o professor, precisa - antes de tudo-ouvir o que ele tem para falar $e$, a partir destas falas e experiências, construir qualquer proposta formativa (MEMORIAL DE FORMAÇÃO, AUTORA/NARRADORA).

Foi assim que planejamos outra perspectiva de experiência formativa, também desenvolvida em formato de oficina, que reuniu professores de três escolas participantes do Pibid, alunos e professores do curso de Licenciatura em Química. Desde o momento da apresentação da atividade pensamos em estratégias para dar voz aos participantes, de modo que aquela participação que ansiávamos que acontecesse no primeiro momento supracitado se efetivasse.

Hoje constato as incoerências presentes no primeiro momento narrado: buscávamos a participação dos professores nas ações propostas, mas, ao mesmo tempo, não consideramos que os mesmos fossem capazes de contribuir na definição dos objetivos da atividade e, inclusive, propusessem redirecionamentos no programa da oficina. Ao contrário, pensamos ser nossa responsabilidade determinar o que eles tinham de aprender sobre a docência.

Nesses termos, passo a considerar que recaímos no equívoco da formação continuada que emudece o professor, conforme expressa Echeverria, Benite e Soares (2007, p. 2):

O professor, frequentemente é apontado como responsável pela má qualidade do ensino. Porém, no histórico da educação, poucas foram as oportunidades dadas a este para que se manifestasse sobre sua prática pedagógica. Ações institucionais nos sistemas educacionais foram sistematicamente introduzidas no âmbito escolar sem que os professores opinassem efetivamente a respeito, sendo considerados profissionais incapazes de referirem-se sobre o que diretamente os afeta.

Os autores denunciam o distanciamento dos professores nas decisões que envolvem os seus próprios processos formativos e os objetivos do ensino que praticam e alertam que tudo isso pode ser uma das razões do inexpressivo envolvimento dos professores da educação básica com as pesquisas realizadas por professores universitários na escola. Isto não quer dizer, no entanto, que o professor não tenha interesse de melhorar sua própria prática e não assuma compromisso com o seu processo formativo, 
mas revela, em grande medida, uma descrença nas pesquisas e iniciativas que tratam da formação docente, porque foi, historicamente, desconsiderado enquanto profissional produtor de conhecimento.

Em um dos resgates da experiência vivida na segunda oficina narrada em meu memorial, recordei da perspectiva do grupo de reorientar o programa da oficina e, como alternativa, uma das primeiras ações era conhecer os professores participantes e suas expectativas para o momento de formação. Assim, propusemos a construção de um Quadro de concepções com dois espaços denominados Desafios da profissão docente e Necessidades formativas, que deveriam ser preenchidos com tarjetas pelos participantes da oficina.

Lembro que a nossa própria expectativa para o momento de construção do quadro era de que surgissem como repostas aos desafios a indisciplina/violência, a infraestrutura física adequada, a ausência de políticas públicas, cargas horárias excessivas, salários defasados, materiais didáticos atualizados e outros desafios tão comuns à discussão sobre a realidade do professor brasileiro.

A tarjeta que nos surpreendeu demonstrava, contudo, o sentimento de solidão docente que também esteve constante na fala dos professores no decorrer da oficina, revelando a urgência do coletivo, da construção de parcerias e da criação de grupos de professores para apoiar o professor no seu processo de desenvolvimento profissional.

Para o preenchimento do espaço das "Necessidades formativas" muitos participantes afirmaram o desejo de retornar ao espaço da universidade em cursos de Pós-Graduação. A realidade de trabalho de boa parte desses participantes, porém, dificulta e, muitas vezes, inviabiliza o retorno do professor para dar prosseguimento à sua formação. Nesse momento "percebi que a formação continuada não é apenas uma questão de 'boa vontade', existem questões sociais, políticas e econômicas que dificultam o retorno do professor para o espaço da universidade" (MEMORIAL DE FORMAÇÃO, AUTORA/NARRADORA). Segundo Zeichner e Diniz-Pereira (2005, p. 71),

No Brasil, apesar de haver iniciativas de parcerias entre universidades e Secretarias de Educação para o desenvolvimento de programas de formação continuada que incluam a realização de pesquisas por parte dos professores, as condições de trabalho da maioria dos educadores são tão precárias que às vezes pode parecer piada de mau gosto falar em pesquisa desenvolvida por professores na escola.

A construção do Quadro de concepções foi decisiva para a ruptura de uma compreensão equivocada que eu possuía antes de trabalhar com a formação de professores. Considerava que a decisão acerca da formação continuada de professores pertence unicamente ao professor. A realidade, contudo, da educação básica, sobretudo no setor público brasileiro, torna o exercício da docência um desgaste físico e mental para o profissional da educação.

Atribuir ao professor a responsabilidade única de manter-se em processo formativo é ignorar que existem outras condições que não apenas o desejo particular do mesmo, dificultando e, muitas vezes, inviabilizando o retorno desse profissional à academia. Zeichner (1993) ressalta que é preciso desenvolver iniciativas que apoiem o trabalho docente e invistam na formação contínua desses profissionais dentro e fora do espaço da escola. 
Ainda a respeito da importância de desenvolver redes de apoio à formação docente, a constituição de parcerias permanentes no processo de formação e profissionalização dos professores poderá contribuir para superar o sentimento de solidão que afeta os profissionais da educação, assim como poderá minimizar o peso da responsabilidade em suas práticas educativas, pois, ao considerar o trabalho colaborativo, será possível integrar diferentes olhares e perspectivas sobre uma mesma realidade.

\section{FORMAÇÃO E PROFISSIONALIZAÇÃO DOCENTE: Contribuições do Sujeito Coletivo}

As experiências formativas que vivenciei ao longo da minha vida, escolarização, academia e docência, me fundamentam na compreensão de que muitas vozes compõem o meu discurso e que eu observo meu trabalho e minhas pesquisas com uma lente construída por muitos olhares e teorias (MEMORIAL DE FORMAÇÃO, AUTORA/NARRADORA).

As experiências mencionadas neste trabalho revelaram os desafios postos à minha atividade docente, ao exercício da reflexão e ao compromisso com a pesquisa. 0 que percorri ao longo de dez anos de experiência como professora de Ciências/Química me fez perceber, na interação com outros sujeitos, que o peso da responsabilidade docente só pode ser suportado na coletividade. Essa compreensão leva-me a assumir, com Fraiha-Martins (2014, p. 84), que é necessário em processos de formação docente "cultivar atitudes do sujeito coletivo, que ensina e aprende em cooperação e colaboração, que não cultua o autoritarismo e que vê no outro uma rica fonte de experiência e de aprendizagem".

Outras vozes possibilitaram reflexão e tomada de consciência sobre algumas ausências no meu percurso formativo e auxiliaram-me na percepção de (re)construções necessárias à minha prática; vozes que ora sistematizo em três categorias de sujeitos que contribuíram/contribuem para o processo de reflexão na/sobre a minha prática: (1) professor-formador; (2) professora-parceira e (3) aluno.

Representando os professores formadores que tive, destaco a pessoa do professor Henrique, que, na experiência da Graduação, "era um dos poucos professores do curso de Química a dedicar-se em estudo e tempo para pensar na formação dos alunos enquanto futuros professores de Química" (MEMORIAL DE FORMAÇÃO, AUTORA/NARRADORA).

A formação de Henrique pautou-se em um caráter técnico ${ }^{9}$, voltado para o atendimento à indústria. O Mestrado em Química Orgânica, por sua vez, não promoveu nenhuma leitura ou discussão voltada para a aprendizagem da docência. Esta realidade representa bem o status quo do perfil de professores que integram os cursos de Licenciatura em Química. "Muitos bacharéis de Química acabam tornando-se professores de Química por força do mercado de trabalho, sem terem tido a mínima formação pedagógica para isso" (MALDANER, 2013, p. 48).

Henrique é bacharel em Química Industrial e foi selecionado via concurso público para atender à demanda da área de Físico-Química no curso de Licenciatura em Química (no período de ingresso na Universidade existia apenas a modalidade de Licenciatura). 
É importante mencionar, contudo, que essa realidade não determina a prática desses bacharéis, uma vez que o processo de formação desses profissionais é contínuo e pode ser redirecionado ao ensino de Química à medida que o profissional compreende a necessidade do desenvolvimento de outras competências para sua atividade docente e para a formação de outros profissionais da docência. Justifico essa proposição porque o professor Henrique é exemplo de um bacharel em Química que investiu continuadamente em seus processos de formação no âmbito da docência para formar professores de Química.

O professor Henrique, em sua condição de formador, preocupava-se com nosso entendimento sobre o ensino de Química na escola. Envolvia-nos em situações de ensino que pudessem nos conduzir ao pensamento prático do professor de Química. A esse respeito, Pérez-Gómez (1992, p. 112) manifesta que

O pensamento prático do professor não pode ser ensinado, mas pode ser aprendido. Aprende-se fazendo e reflectindo na e sobre a acção. Através da prática é possível apoiar e desenvolver o pensamento prático, graças a uma reflexão conjunta (e recíproca) entre o aluno-mestre e o professor ou o tutor (grifos do autor).

Henrique auxiliou-me neste processo de reflexão conjunta mediando meus processos formativos, sendo um importante interlocutor nas situações de pesquisa e de ensino em Química, promovendo situações concretas de formação e incentivando o desenvolvimento da minha autonomia docente. As nossas diferenças em conhecimento e experiência nunca o permitiram "ignorar que eu também poderia contribuir e lhe ensinar algo, que minha trajetória tem sua importância e contribuição para a área que integramos" (MEMORIAL DE FORMAÇÃO, AUTORA/NARRADORA).

Em suas aulas, Henrique propiciava-nos tempo e espaço para praticar, comunicar e discutir sobre o ensino de determinado conteúdo químico. Tais práticas vão ao encontro das proposições de Schnetzler (2002, p. 18) sobre o professor em processo de formação, conforme expressa:

É importante lembrar, ainda, que transformações nas concepções docentes não ocorrem simplesmente pela apresentação de argumentos lógicos e racionais. Os professores precisam vivenciar suas tentativas de inovação e, para isso, é importante que sejam incentivados a apresentá-las ao grupo, recebendo retroalimentações de seus colegas e de seu colaborador universitário.

A oportunidade de ter convivido com o professor Henrique provocou-me o entendimento de que seria no contato com as situações práticas que eu poderia aprender a ser professora de Química ${ }^{10}$. O “incentivo expresso nos empréstimos de livros, nas orientações de leituras, nos momentos de diálogo sobre ensino de Química e a formação docente" (MEMORIAL DE FORMAÇÃO, AUTORA/NARRADORA), permitiram uma aprendizagem da docência que se efetivava nos contextos práticos, quando eu pude construir conhecimentos e melhorá-los.

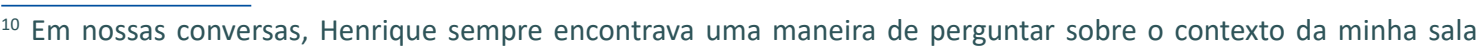
de aula, como eu enfrentava situações complexas. Ele questionava a razão de algumas ações minhas e tentava compreender um pouco sobre a realidade dos meus alunos e, consequentemente, da escola.
} 
"Foram muitos encontros para estudos, produções de trabalhos, participações em Congressos e demais eventos e tudo isso foi fundamental para possibilitar novos encontros, parcerias, trabalhos e pesquisas" (MEMORIAL DE FORMAÇÃO, AUTORA/NARRADORA), possibilitando um novo olhar para a minha própria formação e integrando um princípio hoje indissociável de minha busca pela autoformação, qual seja: "a prática como lugar de aprendizagem e de construção do pensamento prático" (PÉREZ-GÓMEZ, 1992, p. 110).

A interação com o professor-formador Henrique tornou-nos gradativamente professores-parceiros, na medida em que íamos discutindo sobre minhas experiências de docência. Uma de minhas iniciativas que a parceria com Henrique incentivou foi a busca pela Pós-Graduação. O Mestrado surgiu como uma necessidade de encontrar com outros sujeitos que pudessem contribuir para as discussões sobre a formação de professores de Química e, assim como eu, compreendessem a importância da prática reflexiva no processo de formação e exercício da docência.

No Mestrado encontrei Fernanda, licenciada em Química e professora da rede federal de ensino, e nos tornamos professoras-parceiras, assim como eu e o Henrique. Considero a representação do professor-parceiro fundamental em meus processos reflexivos e formativos, porque assumo, com Fraiha-Martins (2014), que a efetivação da parceria docente na profissão do professor pode tornar-se um modo eficaz de dirimir os problemas cotidianos da prática profissional repleta de incertezas e dinamicidade.

Para Fraiha-Martins (2014, p. 124), a parceria é capaz de permitir certas qualidades na interação docente. Dentre elas, a autora destaca a interlocução em nível docente, que é, sobretudo, "a fala de aspectos específicos da área de domínio que sobrevém na conversação docente de modo a contribuir com o planejamento e o ensino integrado de conteúdos e com a autoformação do formador". Isto é, professores-parceiros que dialogam entre si ao refletirem sobre suas práticas docentes, produzindo qualidades discursivas em torno de soluções para determinados problemas em comum de sala de aula, contribuindo para a autoformação docente.

Eu e Fernanda construímos uma parceria que se mantém até os dias atuais, e "nesta parceria compartilhamos as experiências de sala de aula, as atividades que desenvolvemos, as ideias que temos, mas também compartilhamos as angústias da profissão e os desafios que enfrentamos cotidianamente" (MEMORIAL DE FORMAÇÃO, AUTORA/NARRADORA). A interlocução em âmbito docente ocorre entre nós, uma vez que somos docentes em mesmo nível horizontal. Não há hierarquia - professor-formador e licenciando, supervisor e professor ou professor e aluno -; estamos na mesma condição: somos professoras de Química que atuam na rede federal de ensino. Essa condição propicia, em nossa parceria, a construção de discursos e práticas docentes sobre o ensino de Química, que se constrói a partir do outro (interlocutor) e objetiva também o outro (FRAIHA-MARTINS, 2014).

Ademais, venho constituindo-me, ao longo da minha formação e docência, um sujeito coletivo que me faz compreender que nem sempre as parcerias serão possíveis no espaço geográfico que ocupamos. Muitas vezes elas ocorrem a distância e o que nos 
aproxima são os mesmos objetivos. No caso de Fernanda e eu, o que nos aproxima são as pretensões de pesquisa e o desejo de contribuir para o fortalecimento da área de formação de professores de Química enquanto campo científico.

Ao tomar consciência sobre o sujeito coletivo que venho me tornando, não havia como não registrar, em meu memorial de formação, certas situações de aprendizagem da docência com os alunos que interagi e que marcaram profundamente minha trajetória como professora de Química. Destaco Bruna, aluna do primeiro ano de uma escola pública de Ensino Médio. "Repetindo o primeiro ano, vindo transferida de uma escola onde tinha agredido uma colega. Bruna estava diariamente tentando ridicularizar a figura do professor, enfrentando, criando conflitos" (MEMORIAL DE FORMAÇÃO, AUTORA/NARRADORA).

A postura de Bruna não permitia uma convivência tranquila, nem proporcionava uma aproximação natural entre professora e aluna. Bruna tornava o ambiente da sala de aula desgastante e impróprio ao ensino de qualquer área. "Sendo bastante honesta, a convivência com Bruna era tão difícil que muitas vezes fui para casa pensando em como seria bom se ela fosse transferida também dessa escola" (MEMORIAL DE FORMAÇÃO, AUTORA/NARRADORA). A iniciativa de realizar um trabalho diferenciado sobre a história dos elementos químicos para discutir o conteúdo da Tabela Periódica, no entanto, redirecionou nossa convivência em sala de aula.

Iniciamos a construção de painéis para afixar nos corredores da escola, e boa parte dos alunos estava envolvida na confecção dos materiais. Alguns alunos não estavam participando, entre eles, Bruna, mas enquanto os demais demonstravam desprezo pela atividade, ela ficava sentada na carteira, olhando para os painéis em construção e dizendo para os colegas como organizar os símbolos, se aborrecia com aqueles que cometiam erros, mas continuava sentada na sua carteira como quem não queria se envolver ou demonstrar interesse (MEMORIAL DE FORMAÇÃO, AUTORA/NARRADORA).

Observar o envolvimento dos alunos com a atividade é uma etapa importante para avaliação dos resultados da aprendizagem discente. O comportamento de Bruna despertou em mim a compreensão de que havia nela algum interesse sobre o assunto, embora a mesma empreendesse certo esforço para demonstrar indiferença. Registro assim em meu memorial:

Ainda tinha uma cartolina sobrando (aquela do grupo de alunos que não quis participar) e eu decidi entregar para ela. Disse que ela deveria organizar o cartaz e ela me olhou sem dizer nada, mas demonstrou certa surpresa e segurou a cartolina que entreguei. Ela concluiu a atividade, entregou meio desconfiada e eu não fiz nenhum comentário, pois sabia que isso poderia afastá-la. Afixamos os cartazes nos corredores e, ao final do turno, passei para ler com mais calma os cartazes. Para minha surpresa, Bruna ouvia o que eu dizia em sala, ela colocou no cartaz informações que discutimos em aulas anteriores (MEMORIAL DE FORMAÇÃO, AUTORA/ NARRADORA).

Ao contrário do que eu supunha, Bruna prestava atenção às aulas de Química, aprendia o conteúdo e eu não sabia disso porque realizava a avaliação de Bruna a partir dos resultados das provas e do comportamento hostil da aluna. Rememorar esse mo- 
mento me faz entender que eu planejava meus instrumentos de avaliação como um fim em si mesmo, desconsiderando aspectos qualitativos do aluno, como expressa Maldaner $(2013$, p. 398):

Como intelectuais da educação, cabe aos professores colocar em fase o complexo escolar, ou seja, direcionar o processo de tal forma que a recriação cultural, artística e científica possa dar-se de melhor maneira. A avaliação passaria a ser um instrumento de acompanhamento e constante retomada do processo escolar, e não um fim em si mesmo, como é percebida pela maioria dos atuais atores escolares.

Assumir que os alunos são sujeitos neste coletivo, e, sobretudo, importantes para a (continua) formação do professor, é entender que as interações com eles no espaço da escola são capazes de retroalimentar a própria prática de ensino de Química por meio da reflexão docente acerca do que manifestam em aula/sobre a aula. A manutenção do aluno passivo, alheio ao processo educativo, vai na contramão da ideia do coletivo na sala de aula e inviabiliza uma reorientação da prática docente às demandas de cada contexto.

A sala de aula, pensada na perspectiva de ambiente de investigação e de formação, pressupõe a emancipação de todos os sujeitos à condição de pesquisadores: sejam eles professores ou alunos. Assim como o professor-formador e o professor-parceiro, portanto, o aluno constitui-se "outro sujeito" que, inserido em movimentos de interação e de reflexão sobre docência, contribui para a formação e a profissionalização docente.

\section{REFLEXÕES FINAIS: Princípios Formativos Emergentes}

[...] percebo o quanto a minha prática tem mudado ao longo do tempo pela oportunidade de estar em contato com pessoas diferentes, partilhando experiências e conhecimento, fomentando momentos de reflexão para romper com o fluxo que o trabalho docente acaba gerando: ações irrefletidas, mecanizadas e desconexas (MEMORIAL DE FORMAÇÃO, AUTORA/NARRADORA).

Os processos de reflexão docente pelos quais passei nesta investigação revelam que vivenciei movimentos de formação e docência que demarcaram significativamente minha trajetória profissional, os quais passo a configurar como desejáveis à formação de professores de Química. São movimentos formativos que devem circunscrever os seguintes princípios: (1) a escola é lugar de aprendizagem da docência; (2) o exercício da pesquisa e reflexão é indissociável da formação e da prática docente; (3) parcerias potencializam a construção coletiva de novas práticas.

Ao buscar as experiências vividas no contexto da escola básica, como aluna e professora, identifiquei fragilidades de minha formação inicial que provocaram uma sensação de insegurança no início da carreira docente. A Licenciatura não contempla a escola básica em suas discussões para a formação inicial do professor de Química e, ao concluir a Graduação, o licenciado não é apoiado no início da profissão, o que explica bem o sentimento, identificado neste trabalho como solidão docente.

A respeito da escola como lugar de aprendizagem da docência, não estou me referindo à escola em suas estruturas físicas das salas de aula, mas ao conjunto plural que ela representa: sua história, suas lutas, seu caráter intrinsecamente social e polí- 
tico que precisam fazer parte da formação docente desde os primeiros momentos da Licenciatura, sendo problematizados. 0 resgate das minhas memórias de formação me fez perceber que a escola é lugar de aprendizagem! Sobre isso sempre houve consenso, mas a referência à aprendizagem sempre remeteu aos alunos, contudo é fundamental recorrer ao potencial do contexto escolar para viabilizar a aprendizagem da docência na/sobre a prática.

Ainda discutindo a importância de o processo formativo docente se estabelecer na e sobre a realidade escolar, encontro o segundo princípio: a premência de assumir a pesquisa e a reflexão como recursos indissociáveis da formação e da prática docente (ROSA; MENDES; LOCATELLI, 2018). Encontrei na reflexão sobre a ação, induzida pela pergunta "Porque ensino do jeito que ensino?", condições para pensar as fragilidades da minha formação e a necessidade de transformar minha prática. Este movimento me fez despertar para a importância da pesquisa nos contextos de formação de professores de Química. A pesquisa de professores defendida aqui retira o professor da condição de objeto investigado para assumir o papel de investigador da sua própria prática, identificando desafios, propondo sugestões, desenvolvendo ações, avaliando resultados e redirecionando ações.

O terceiro princípio, resultado desta investigação narrativa autobiográfica sobre o meu processo de formação e desenvolvimento profissional, revela a constituição de parcerias. Esta pesquisa permitiu um reencontro com outros sujeitos que, nas especificidades de suas relações, podem contribuir com a formação de professores e reduzir a sensação de solidão tão comum aos profissionais da educação.

Nestas parcerias encontrei um sujeito coletivo que me direcionou nos processos reflexivos sobre a minha prática, permitindo rupturas com concepções equivocadas sobre o ensino de Química e sobre a minha própria formação para atendimento desse ensino. Encontrar parceria em processos de formação inicial ou continuada retira o professor do isolamento e sugere uma nova compreensão de responsabilidade sobre o ensino que pratica.

\section{REFERÊNCIAS}

CARVALHO, Ana Maria Pessoa; GIL-PÉREZ, Daniel. Formação de professores de ciências: tendências e inovações. 8. ed. São Paulo: Cortez, 2006. (Coleção questões da nossa época; v. 26).

CLANDININ, Jean; CONNELLY, Michael. Pesquisa narrativa: experiências e história na pesquisa qualitativa. Tradução Grupo de Pesquisa Narrativa e Educação de Professores ILEEL/UFU. Uberlândia: Edufu, 2011.

CONTRERAS, José. A autonomia de professores. Trad. Sandra Trabucco Valenzuela. São Paulo: Cortez, 2002.

ECHEVERRIA, Agustina Rosa; BENITE, Ana Maria Canavarro; SOARES, Márlon Herbert Flora Barbosa. A pesquisa na formação inicial de professores de Química - a experiência do Instituto de Química da Universidade Federal de Goiás. In: REUNIÃO ANUAL DA SOCIEDADE BRASILEIRA DE QUÍMICA, 30. 2007. Anais [...]. 2007. p. 1-19. Disponível em: http://www.sbq.org.br/30ra/Workshop\%20UFG.pdf. Acesso em: 23 nov. 2020.

FERRAROTTI, Franco. Sobre a autonomia do método biográfico. In: NÓVOA, Antônio; FINGER, Matthias (org.). O método (auto) biográfico e a formação. São Paulo: Editora Paulus, 2010. p. 32-57.

FRAIHA-MARTINS, France. Significação do ensino de ciências e matemática em processos de letramento científico-digital. 2014. 235 f. Tese (Doutorado em Educação em Ciências e Matemática) - Universidade Federal do Pará, Programa de Pós-Graduação em Educação em Ciências e Matemáticas, Belém, 2014. 
HUBERMAN, Michael. O ciclo de vida profissional dos professores. In: NÓVOA, António (org.). Vidas de professores. 2. ed. Cidade de Porto: Porto Editora, 2000.

IMBERNÓN, Francisco. Formação docente e profissional: formar-se para a mudança e a incerteza. 6. ed. São Paulo: Cortez, 2006. (Coleção Questões da Nossa Época).

JOSSO, Marie Christine. Experiências de vida e formação. São Paulo: Cortez, 2004.

JOSSO, Marie Christine. A transformação de si a partir da narração de histórias de vida. Educação, Porto Alegre, RS, a. XXX, n. 3 (63), p. 413-438, set./dez. 2007. Disponível em: https://wp.ufpel.edu.br/gepiem/ fi-les/2008/09/a_tranfor2.pdf. Acessado em: 10 out. 2020.

JOSSO, Marie Christine. Da formação do sujeito... ao sujeito da formação. In: NÓVOA, A.; FINGER, M. (org.). O método (auto) biográfico e a formação. Natal, RN: EDUFRN; São Paulo: Paulus, 2010.

MACENO, Nicole Glock; GUIMARÃES, Orliney Maciel. O programa Institucional de Bolsas de Iniciação à Docência e o desafio de ressignificar a docência. Revista Contexto \& Educação, n. 93, p. 108-137, maio/ ago. 2014. Disponível em: Academia.edu. Acesso em: 18 nov. 2020.

MALDANER, Otavio Aloisio. Formação inicial e continuada de professores de química: professor pesquisador. 4. ed. ljuí: Editora Unijuí, 2013.

MORAES, Roque; GALIAZZI, Maria do Carmo. Análise textual discursiva. Ijuí: Editora Unijuí, 2016.

NÓVOA, António. A formação tem que passar por aqui: as histórias de vida do Projeto Prosalus. In: NÓVOA, António.; FINGER, Mathias (org.). O método (auto)biográfico e a formação. Natal: EDUFRN; São Paulo: Paulus, 2010. p. 155-187.

PÉREZ-GÓMEZ, Angel. "O pensamento prático do professor - a formação do professor como profissional reflexivo". In: NÓvOA, António. Os professores e sua formação. Lisboa: Publicações Dom Quixote, 1992. p. 93-113.

RIBEIRO, Alcione Torres; BEJARANO, Nelson Rui Rios; SOUZA, Elizeu Clementino. Formação inicial em serviço de professores de química da Bahia: história de uma vida. Química Nova na Escola, n. 26, p. 13-16, nov. 2007. Disponível em: http://qnesc.sbq.org.br/online/qnesc26/v26a04.pdf. Acesso em: 11 dez. 2020.

ROSA, Débora Lázara; MENDES, Ana Néry Furlan; LOCATELLI, Andrea Brandão. A sistematização dos saberes docentes em suas relações com a formação inicial de professores de Química. Revista Contexto \& Educação, n. 105, p. 68-94, maio/ago. 2018. Disponível em: https://www.researchgate.net/publication/326053762. Acesso em: 15 nov. 2020.

SCHNETZLER, Roseli Pacheco. Concepções e alertas sobre formação continuada de professores de Química. Química Nova na Escola, n. 16, p. 15-20, 2002. Disponível em: http://qnesc.sbq.org.br/online/ qnesc16/v16_A05.pdf. Acesso em: 17 nov. 2020.

ZEICHNER, Kenneth Michael; DINIZ-PEREIRA, Júlio Emílio. Pesquisa dos educadores e formação docente voltada para a transformação social. Cadernos de Pesquisa, v. 35, n. 125, p. 63-80, maio/ago. 2005. Disponível em: http://www.scielo.br/scielo.php?pid=S0100-15742005000200005\&script=sci_abstract\&tln$\mathrm{g}=$ pt. Acesso em: 12 nov. 2020.

ZEICHNER, Kenneth Michael. A formação reflexiva de professores: idéias e práticas. Lisboa: Educa, 1993.

ZEICHNER, Kenneth Michael. Para além da divisão entre professor-pesquisador e pesquisador acadêmico. In: GERALDI, Corinta Maria Grisólia; FIORENTINI, Dario; PEREIRA, Elizabete Monteiro (org.). Cartografias do trabalho docente. Campinas: Mercado das Letras; ALB, 1998. p. 207-236. 